IOSR Journal of Pharmacy

ISSN: 2250-3013, www.iosrphr.org

\||| Volume 2 Issue 4 \||| July-August 2012 ||| PP.01-03

\title{
Prevalence and incidence of byssinosis in ginning mill factory workers
}

\author{
Dr Sujatha Talikoti ${ }^{1}$, Dr Anand.N.Patil ${ }^{1}$, Dr Manjunatha. $A^{2}$, Dr \\ Sumangala.patil'. \\ 1. Assisstant professor Department of Physiology BLDE University Sri B M Patil Medical College and Research \\ Center BIJAPUR-586103; KARNATAKA. \\ 1. Associate professor Department of Medicine Al-Ameen Medical College BIJAPUR-586103; KARNATAKA. \\ 2. Dr Manjunatha .A. Professor and HOD Department of Physiology bldeus Sri B M Patil Medical College and \\ Research Center. BIJAPUR-586103; KARNATAKA. \\ 2. Dr Sumangala. Patil. Professor Department of Physiology bldus Sri B M Patil Medical College . BIJAPUR- \\ 586103; KARNATAKA.
}

\begin{abstract}
-
Background: Occupational exposure to cotton flax and hemp dust leads to a disabling lung disease known as, Byssinosis has been shown develop in response to dust exposure in cotton processing.

Byssinosis is characterized by shortness of breath and chest tightness. In Northern part of Karnataka, there are many ginning factories associated with processing of cotton. The present study therefore was under taken to evaluate the incidence and prevalence

Materials and methods: The study is conducted on 110 workers of ginning factory situitaed in BIJAPUR. District North Karnataka. 50 control subjects were selected from non-teaching staff BLDRA'S Sri B M Patil medical college Bijapur. The study subjects were divided in to

Group-I [67 who actually work with cotton and directly exposed to cotton dust].

Group-II [43 workers who are not directly exposed to cotton dust but working in other departments of mill].Assessment of workers suffering from byssinosis done for-Group-I \& II , by using questionnaires designed by Murlidhar based on Schillong's recommendations for diagnosis of byssinosis [recording] of occupational history was also taken . Statistical analysis was done by ' $Z$ ' TEST to calculate level of significance. ANOVA test was applied to compare the mean values of various groups

Results: In the present study, we observed that $8.95 \%$ of workers directly exposed to cotton dust suffered from byssinosis. Those in Group -II did not show any signs of byssinosis. Depending upon the age group of the subjects, chronic bronchitis [13], chronic cough [21], chronic phlegm [9]. Grade wise analysis of byssinotic, shows that 6 are suffering from byssinosis, 4 suffering from Grade-1,2 from Grade-II none of them suffered from either Grade - 1/2 or III of byssinosis.

Conclusion: The prevalence of byssinosis and other respiratory symptoms increased with increase in duration of exposure and advancement of age.
\end{abstract}

Keywords—Byssinosis, pulmonary function tests.

\section{OBJECTIVE} Byssinosis.

Occupational exposure to cotton flax \& hemp dust, leads to a disabling lung disease known as,

It has been shown to develop in response to dust exposure in cotton processing.

It is especially prevalent among cotton workers in the initial very dusty operations where flakes are broken open ${ }^{1}$.

Byssinosis is characterized by shortness of breath \& chest tightness.

In Northern part of Karnataka ,there are many Ginning factories associated with processing of cotton .

The present study therefore was undertaken to evaluate the incidence and prevalence of byssionosis among such workers to assess magnitude of the problem².

\section{MATERIALS AND METHOD}

The study is conducted on 110 workers of a ginning factory situiatated in Bijapur, District North Karnataka . 50 control subjects were selected from non-teaching staff BLDEA'S Sri B M Patil medical college Bijapur. The study subjects were divided in to Group-I (67 who actually work with cotton \& directly exposed to cotton dust). 
Group-II (43 workers who are not directly exposed to cotton dust but working in other departments of mill). Assessment of workers suffering from byssinosis done for Group-I\&II, By using questionnaires designed by Murlidhar based on Schillong's ${ }^{3,4}$ recommendations for diagnosis of byssinosis (recording) of occupational history was also taken.

Statistical analysis was done by' Z' test to calculate level of significance.

ANOVA test was applied to compare the mean values of various groups.

\section{RESULTS}

Assessment of workers suffering from byssinosis done for Group-I\&II,

In the present study, we observed that $8.95 \%$ of workers were directly exposed to cotton dust suffered from byssinosis.

Those in Group-II did not show any signs of byssinosis. The prevalence of byssinosis in the present study is very low.

One of the important cause of this may be exposure period of the subjects to cotton dust. Depending upon duration of exposure the respiratory signs \& symptoms are analysed.

Depending upon the age group of these subjects chronic bronchitis(13),chronic cough(21),chronic phlegm(9).

Grade wise analysis of byssinotic, shows that 6 are suffering from

byssinosis, 4 suffering from Grade -I, 2 from Grade-II.

None of them suffered from either Grade-1/2 or Grade III of byssinosis.

Table: Prevalence of Respiratory Symptoms and Byssinosis in both Group I and II subjects values within the brackets indicates the percentage of subjects in that particular group

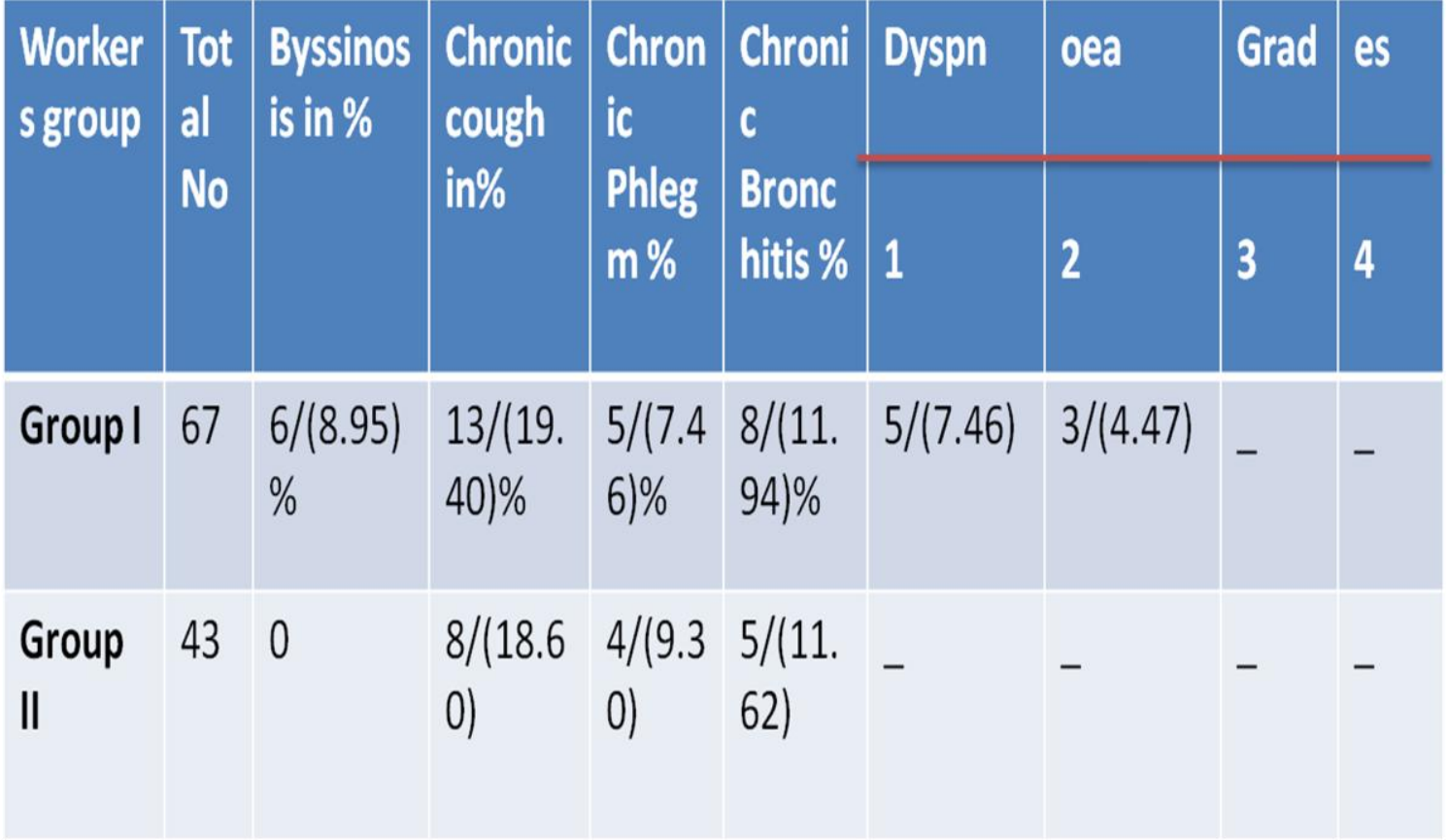

\section{ISCUSSION} byssinosis.

In the present study, we observed that $8.95 \%$ of workers directly exposed to cotton dust suffered from

This finding is in agreement with the findings of other researcher's world over,

Which had shown that workers working in most dusty section of the mill are primarily affected by byssinosis 5 . byssinosis.

In the present study, we observed that $8.95 \%$ of workers directly exposed to cotton dust suffered from

This finding is in agreement with the findings of other researcher's world over,

Which had shown that workers working in most dusty section of the mill are primarily affected by byssinosis ${ }^{5}$. workers in our study suffer from various other type of respiratory symptoms like chronic bronchitis, chronic phlegm and chronic cough in addition $8.95 \%$ workers suffering from byssinosis.

This is consistent with the observations of Bouhuys $A^{5 .}$ All these workers observed deterioration of lung function and appearance of various respiratory symptoms in workers who are exposed to cotton dust for 10 to 20 years. 


\section{CONCLUSION}

The prevalence of byssinosis \& other respiratory symptoms increased with increase in duration of exposure \& advancement of age.

Exposure to cotton dust results in decrease in pulmonary function parameters in worker at both dusty and non-dusty section of mill, which may result in onset of various respiratory disorders. These affects increase with time in duration of exposure and advancement of age.

\section{BIBILOGRAPHY}

[1]. 1 Schilling RSF. "World wide problems of byssinosis". chest:1981:79: 3-55.

[2]. 2 Murlidhar V, Murlidhar VJ. Kahere V. "Byssinosis in a Bombay textile mill”. Natl Med J India; 1995 Sep-Oct: 8(5): $204-7$.

[3]. 3 Gupta MN."Review of byssinosis in India". Indian J Med Res: 1969: 57:1776-89. El Batawi MA,

[4]. 4 Schilling RSF,Valic F, Warford J. "Byssinosis in Egyptian cotton industry: Change in ventilatory capacity during the day". Br J Ind Med:1964: 27:225- 234

[5]. 5 Bouhuys A, Heaply LJ, Schilling RSF, et al: "Byssinosis in the United States". N Engl J med; 1967:277:170.

[6]. 6 El Batawi MA, Schilling RSF,Valic F, Warford J. "Byssinosis in Egyptian cotton industry: Change in ventilatory capacity during the day". Br J Ind Med:1964: 27:225- 234. 